\title{
Improvement in Power Transfer Capability of an Interconnected Power System without Contingency
}

\author{
Gurjot Singh ${ }^{1}$, Harsh Sharma ${ }^{2}$ \\ ${ }^{1}$ B.B.S.B.E.C Fatehgarh Sahib \\ ${ }^{2}$ Assistant Professor, Electrical Engineering Department B.B.S.B.E.C Fatehgarh Sahib
}

\begin{abstract}
Power Transfer Capability is an important index in today's power markets with large volume of inter-area power exchanges and wheeling transactions taking place on hourly basis. Its computation helps to achieve a viable technical and commercial transmission operation. The aim of my research was to evaluate power transfer capability and also to improve it using compensation technique. Load flow of 30-bus system was carried out considering normal conditions without contingency. Base and optimized results shows that how compensation helps to improve system condition and tie-flows. Parameters like voltage magnitude, L-index, MW losses, $M S V$ are computed to analyze the system performance.
\end{abstract}

Keywords: L-index, reactive optimization, reactive compensation, voltage stability

\section{Introduction}

Power transfer capability improvement in today's market is used by the system operators to determine the ability of transmission system to transfer power and by the system planners to indicate the system strength. It is an important index in power markets with large volume of inter-area power exchanges and wheeling transactions taking place on hourly basis. Its computation helps to achieve a viable technical and commercial transmission operation. Also it is necessary to find the capacity usage of different transactions happening at the same time so that a fair use-of transmission-system charge can be given to individual customer separately. In additional, the capacity usage is another important issue for transmission congestion managements; therefore, the power produced by each generator and consumed by each load through the network should be traced and improved. In these aspects, problems arise because all transactions have to share the same transmission network simultaneously. Those problems including " which line no, generators are supplying this load?' 'Which generator or load is making the biggest usage of this transmission line?' and 'Which line, generator or load is producing loss of this transmission line?' etc., need to have acceptable solutions in a fair deregulated power system.

The aim of my research is to evaluate power transfer capability and also to improve it using reactive compensation technique. Load flow of 30-bus system is carried out considering without contingency conditions. Base and optimized results show how compensation helps to improve system conditions. Parameters like voltage magnitude, severity index, MW losses, MSV are computed to analyze the system performance.

\section{- Voltage Stability Analysis \\ - Minimum Singular Value}

Minimum singular value (MSV) of the load flow jacobian, proposed by Lof et al. (1993) is a measure of voltage stability. The singularity of the power flow jacobian matrix is used for determining steady-state stability. Singularity of the power flow jacobian matrix indicates that the inverse does not exist and thus there is an infinite sensitivity in the solution to small perturbations in the parameter values. The MSV is used to indicate the distance between the studied operating point and the steady-state voltage stability limit. At the point of voltage collapse, no physically meaningful load flow solution is possible as the load flow jacobian becomes singular and at this point, the MSV becomes zero. Hence, the distance of the MSV from zero at an operating point is a measure of proximity to voltage collapse. The power flow Jacobian matrix can hence be written as which is a matrix composed of the four sub matrices: $J_{1}, J_{2}, J_{3}$, and $J_{4}$. Since there is a relatively strong coupling between reactive power and voltage magnitudes in the power system, the most interesting of the four sub matrices above is the one which contains the partial derivatives of reactive powers with respect to voltages, above denoted $\mathrm{J}_{4}$. Another way of showing the significance of the matrix Gs as a static voltage stability indicator is to compute the determinant of the power flow Jacobian matrix with the use of Schur's formula. Under the assumption that the sub matrix $J_{1}$ is non singular, and then the determinant of the power flow Jacobian matrix can be calculated.

As $\operatorname{det} \mathrm{J}=\operatorname{det} \mathrm{J}_{1} * \operatorname{det} \mathrm{G}_{\mathrm{s}}$

and

$\mathrm{G}_{\mathrm{s}=J_{4}}-J_{3} * J_{1}^{-1} * J_{2}$

Where $G_{s}$ (Schur's complement) again is defined as can be seen from equation above, the power flow jacobian matrix will become singular either when the matrix $\mathrm{G}_{\mathrm{s}}$ or when the matrix $\mathrm{J}_{1}$ becomes singular. If there are no static angle stability problems, i.e. det $\mathrm{J}_{1} \sim 0$, then the power flow Jacobian matrix will become singular if and only if the matrix Gs becomes singular. The matrix Gs is hence a sub matrix, associated with the matrix $\mathrm{J}$, that is indicative of steady-state voltage stability problems. The use of Gs for voltage stability analysis was proposed in, where the determinant of this sub matrix was presented as an example of a steady-state voltage stability index. 


\section{International Journal of Science and Research (IJSR) \\ ISSN (Online): 2319-7064}

Index Copernicus Value (2013): 6.14 $\mid$ Impact Factor (2015): 6.391

- Calculation of L-index and its importance

Kessel and Glavitsch (1986) have proposed Static voltage stability index named as ' $L$ ' based on normal load flow solution. The value of $\mathrm{L}$ must lie within a unit circle, with a range $\mathrm{L}=0$ (no load on the system) to $\mathrm{L}=1$ (static voltage stability limit). The value of $\mathrm{L}$ is computed for each load bus in the system. Consider a system where $\mathrm{n}$ is total number of busses, with $1,2 \ldots, \mathrm{g}$ generator busses $(\mathrm{g}), \mathrm{g}+1, \mathrm{~g}+2, \mathrm{~g}+\mathrm{s}$, the remaining busses $(\mathrm{r}=\mathrm{n}-\mathrm{g}-\mathrm{s})$. A load flow result is obtained for a given system operating condition, Using the load flow results, the L-index [1] is computed as:

$$
L_{j}=\left|1-\sum_{i=1}^{i=g} F_{j i} * V_{i} / V_{j}\right|_{j=g+1}
$$

The values of the $F_{j i}$ is obtained from the load flow Y-Bus matrix:

$$
\left[\begin{array}{c}
I_{g} \\
I_{l}
\end{array}\right]=\left[\begin{array}{l}
Y_{G G} Y_{G L} \\
Y_{L G} Y_{L L}
\end{array}\right]\left[\begin{array}{c}
V_{G} \\
V_{L}
\end{array}\right]
$$

Values of [IG], [IL] and [VG], [VL] represents the complex currents and bus voltages;

$\left[Y_{G G}\right],\left[Y_{G L}\right],\left[Y_{L G}\right]$ and $\left[Y_{L L]}\right.$ are the matrix Y-bus matrix. From here the values of [FLG] was obtained as:

$[\mathrm{FLG}]=-\left[\mathrm{YLL}^{-1}[\mathrm{YLG}]\right.$

Significance of severity index: The values of severity index lies in between 0 and 1 . Values less than 1 and close to zero indicates that there is improvement in voltage stability. As the load/generation values increases the voltage magnitude and angle changes the voltage stability index $\mathrm{Lj}_{\mathrm{j}}$ value for each load bus tends to get close to 1 , indicating that the system is close to voltage collapse.

\section{Fuzzy Approach for Contingency Ranking}

Fuzzy logic approach is used to identify the most critical line contingencies. The parameters considered for ranking areline loading, bus voltage profiles and L- index values of the load buses. The post-contingent quantities are first expressed in fuzzy set notation before they can be processed by the fuzzy rules. The details of the fuzzy approach are given by Vishaka et. al. (2004).

\section{- Line Loading:}

Each post-contingent percentage line loading is divided into four categories using fuzzy set notations: lightly loaded (LL), 0-50\%; normally loaded (NL), 50-85\%; fully loaded (FL), $85-100 \%$; over loaded (OL), above $100 \%$.

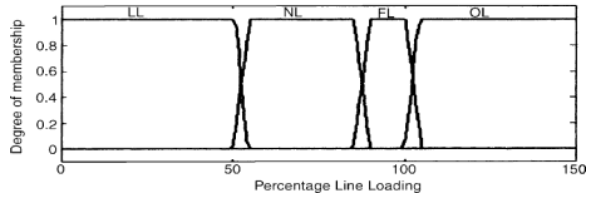

Figure 1

\section{- Bus voltage profiles:}

Each post-contingent bus voltage profile is divided three categories using fuzzy set notations: low voltage (LV), below 0.9 p.u.; normal voltage (NV), 0.9-1.02 p.u. and over voltage (OV), above 1.02 p.u.

\section{- Voltage stability indices:}

Each post-contingent voltage stability index is divided into five categories using fuzzy set notations: very low index (VLI), 0-0.2; low index (LI), 0.2-0.4; medium index (MI), $0.4-0.6$; highindex $(\mathrm{HI}), 0.6-0.8$ and very high index (VHI), above 0.8 .

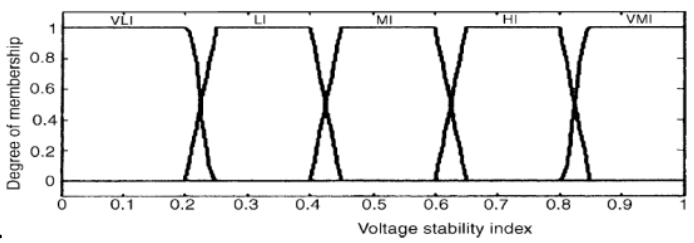

Figure 2

\section{Algorithm}

1. Form $Y_{\text {bus }}$.

2. Given: Base case system's transmission data, load data information.

3. Solve the power flows for the base case data, checking for no limit violations.

4. Obtain the sub matrix of the Y-BUS matrix that is connected through load to generator and load to load as $\mathrm{Y}_{\mathrm{LG}}$ and $\mathrm{Y}_{\mathrm{LL}}$

5. Calculate the $Y_{\text {bus }}$ matrix from that find out the sub-matrix of the Y-matrix as:

$\mathrm{Y}_{\mathrm{bus}}=\left[\begin{array}{l}Y_{G G} Y_{G L} \\ Y_{L G} Y_{L L}\end{array}\right]$

6. After finding the SUB-Matrix from Y-BUS matrix formulate the severity index as L-INDEX which is formulated as:

$L_{j}=\sum_{i=1}^{i=g} F_{j i} \times V_{i} / V_{j}$

Where $\mathrm{j}=\mathrm{g}+1, \ldots \ldots, n$.

7. The value of $F_{j i}$ is found out.

8. After this with the optimization technique find the value of $V_{L}$ which is given as $V_{L}=\sum_{j=g+1}^{n}\left(L_{j}\right)^{2}$ 


\section{International Journal of Science and Research (IJSR) \\ ISSN (Online): 2319-7064}

Index Copernicus Value (2013): 6.14 | Impact Factor (2015): 6.391

9. The secure voltage limits are set between $0.9 \leq \mathrm{V} \leq 1.05$ and secure line loading is set between $50 \%-110 \%$ of its rated value.

10. Identify the zone to zone interfaces.(zone-1 and zone-2)

11. Check the solution for violations of operational or physical limits. If there are violations, decrease the transfer power to the minimum amount necessary to eliminate them.

12. Identify the critical lines in each zone and rank them. To rank the critical contingencies NCOSI is computed using fuzzy logic approach as given below, and based on this index the single line contingencies are ranked.

$N C O S I=\sum W_{L L} S I_{L L}+\sum W_{V P} S I_{V P}+\sum W_{V S I} S I_{V S I}$

13. Identify the optimal locations for the reactive power compensation. The optimal reactive compensation location is selected after studying the system performance under critical line without contingency conditions.

14. STOP.

\section{Single Line Diagram: IEEE 30-Bus System}

ZONE-1 from 1-15

ZONE-2 from $16-30$

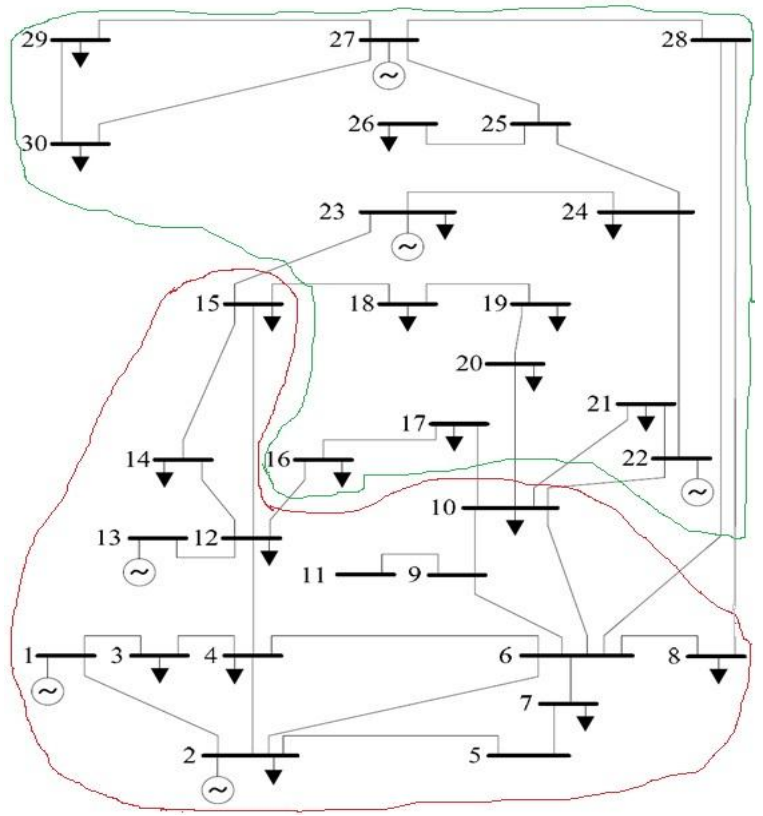

Figure 3

\section{Results and Discussion}

Results for Zone-1: Line No-3 without contingency under reactive compensation.

Table 1

\begin{tabular}{|c|c|c|}
\hline \multicolumn{3}{|c|}{ Critical lines for Zone-1(without contingency) } \\
\hline \multirow{3}{*}{ Parameters } & $\begin{array}{c}\text { Without reactive } \\
\text { compensation at }\end{array}$ & $\begin{array}{c}\text { With reactive } \\
\text { compensation at }\end{array}$ \\
\cline { 2 - 3 } & Line No. 3 & Line No. 3 \\
\hline$\sum L^{2}$ & 0.0114 & 0.0329 \\
\hline $\mathrm{V}_{\min }$ (p.u.) & 0.6362 & 0.8071 \\
\hline P-Loss (MW) & 71.94 & 25.57 \\
\hline MSV & 1.0485 & 1.8612 \\
\hline \multicolumn{2}{|c|}{ Selected Line } & $\mathrm{x}$ \\
\hline
\end{tabular}

Line No-4: Without contingency under reactive compensation

Table 2

\begin{tabular}{|c|c|c|}
\hline \multicolumn{3}{|c|}{ Critical lines for Zone-1(without contingency) } \\
\hline \multirow{2}{*}{ Parameters } & $\begin{array}{c}\text { Without reactive } \\
\text { compensation at }\end{array}$ & $\begin{array}{c}\text { With reactive } \\
\text { compensation at }\end{array}$ \\
\cline { 2 - 3 } & Line No. 4 & Line No. 4 \\
\hline$\sum L^{2}$ & 0.0171 & 0.0428 \\
\hline $\mathrm{V}_{\min }$ (p.u.) & 0.8501 & 0.9070 \\
\hline P-Loss (MW) & 71.94 & 13.04 \\
\hline MSV & 1.0485 & 6.8713 \\
\hline \multicolumn{2}{|c|}{ Selected Line } & $\sqrt{ }$ \\
\hline
\end{tabular}

Results for Zone-2: Line No-18 without Contingency with Reactive Compensation

Table 3

\begin{tabular}{|c|c|c|}
\hline \multicolumn{3}{|c|}{ Critical lines for Zone-1(without contingency) } \\
\hline \multirow{2}{*}{ Parameters } & $\begin{array}{c}\text { Without reactive } \\
\text { compensation at }\end{array}$ & $\begin{array}{c}\text { With reactive } \\
\text { compensation at }\end{array}$ \\
\cline { 2 - 3 } & Line No. 18 & Line No. 18 \\
\hline$\sum L^{2}$ & 6.4317 & 4.8677 \\
\hline $\mathrm{V}_{\min }$ (p.u.) & 0.9083 & 0.9086 \\
\hline P-Loss (MW) & 71.94 & 13.01 \\
\hline MSV & 1.0485 & 7.1879 \\
\hline \multicolumn{2}{|r}{ Selected Line } & $\mathrm{x}$ \\
\hline
\end{tabular}

Line No-26: Without Contingency under Reactive Power Compensation

Table 4

\begin{tabular}{|c|c|c|}
\hline \multicolumn{3}{|c|}{ Critical lines for Zone-1(without contingency) } \\
\hline \multirow{2}{*}{ Parameters } & $\begin{array}{c}\text { Without reactive } \\
\text { compensation at }\end{array}$ & $\begin{array}{c}\text { With reactive } \\
\text { compensation at }\end{array}$ \\
\cline { 2 - 3 } & Line No. 26 & Line No. 26 \\
\hline$\sum L^{2}$ & 0.1687 & 0.3399 \\
\hline $\mathrm{V}_{\min }$ (p.u.) & 0.8897 & 0.9059 \\
\hline P-Loss (MW) & 71.94 & 12.88 \\
\hline MSV & 1.0485 & 9.4945 \\
\hline \multicolumn{2}{|c|}{ Selected Line } & $\sqrt{ }$ \\
\hline
\end{tabular}

\section{Conclusion}

In this research of improvement in an interconnected power system a 30-bus system have been studied. In which from two zones the critical lines have been identified and these critical lines have been studied without contingency under reactive power compensation technique and results shows that in zone- 1 the line no -4 proves to be best with all the system parameters. And in zone -2 the line no -26 proves to be best with all the system parameters improved. These two lines from both zones can be used for power transfer. Therefore the results for both the zones have shown an improvement in the system stability and power transfer capability.

\section{References}

[1] Thukaram Dhadbanjan, Vyjayanthi Chintamani "Evaluation and improvement of total transfer capability in an interconnected power system" International journal of emerging electric power systems, vol 11, 2010.

\section{Volume 5 Issue 6, June 2016 www.ijsr.net}


[2] M.A. Khaburi, M.R. Haghifam, "A probabilistic modeling based approach for Total Transfer Capability enhancement using FACTS devices", Electrical Power and Energy Systems, Vol. 32, pp.12-16, 2010.

[3] K. Visakha, D. Thukaram, Lawrence Jenkins, "Application of UPFC for system security improvement under normal and network contingencies", Electric Power Systems Research, Vol. 70, pp. 46-55, 2004.

[4] R. F. Chang, C. Y. Tsai, C. L. Su, and C. N. Lu, "Method for computing probability distributions of available transfer capability", Proc. Inst. Elect. Eng., Gen., Transmission. Distribution. Vol. 149, No. 4, pp. 427431, Jul. 2002.

[5] Ejebe GC, Tong J, Waight JG, Frame JG, Wang X, and Tinney WF., "Available transfer capability calculations", IEEE Trans Power Syst,Vol.13, No.4, 1521-7, 1998.

[6] Gan D, Luo X, Bourcier DV, Thomas R.J., "Min-max transfer capability study preliminary results", In: Proceedings of IEEE power engineering society winter meeting, Vol. 1, 2001. .

[7] G. Hamoud, "Assessment of available transfer capability of transmission systems", IEEE Trans. Power Syst., Vol. 15, No. 1, pp. 27-32, Feb. 2000.

[8] B. Gao, G.K. Morison, and P. Kundur, "Towards the development of a systematic approach for voltage stability assessment of large-scale power systems", IEEE Trans. Power Syst., Vol. 11, No. 3, pp. 1314-1324, Aug. 1996.

[9] Chiang H, Flueck AJ, Shah KS, and Balu N., "CPFLOW: a practical tool for tracing power system steady-state stationary behavior due to load and generation variations", IEEE Trans Power System, Vol. 10, No. 2, pp. 623-634, 1995.

[10] Kessel, P., and Glavitsch, H., "Estimating the voltage stability and load ability of power systems", IEEE Trans. Power Deliv., Vol. 1, No. 3, pp. 1586-1599, 1986 